Published in final edited form as:

Int J Cancer. 2017 March 01; 140(5): 1020-1026. doi:10.1002/ijc.30518.

\title{
Periodontal disease and risk of non-Hodgkin lymphoma in the Health Professionals Follow-up Study
}

\author{
Kimberly A. Bertrand ${ }^{1}$, Janki Shingala ${ }^{2}$, Andrew Evens ${ }^{3}$, Brenda M. Birmann ${ }^{4}$, Edward \\ Giovannucci $^{5}$, and Dominique S. Michaud ${ }^{6}$ \\ ${ }^{1}$ Slone Epidemiology Center at Boston University, Boston, MA \\ ${ }^{2}$ Tufts University, Medford, MA \\ ${ }^{3}$ Division of Hematology/Oncology, Tufts Medical Center, Boston, MA \\ ${ }^{4}$ Channing Division of Network Medicine, Brigham and Women's Hospital and Harvard Medical \\ School, Boston, MA \\ ${ }^{5}$ Departments of Nutrition and Epidemiology, Harvard T.H. Chan School of Public Health, Boston, \\ MA
}

${ }^{6}$ Department of Public Health and Community Medicine, Tufts University School of Medicine, Boston, USA

\section{Abstract}

Periodontal disease is a chronic inflammatory condition that has been associated with chronic diseases, including cancer. In an earlier prospective cohort analysis within the Health Professionals Follow-Up Study (HPFS), we observed a 31\% higher risk of non-Hodgkin lymphoma (NHL) among participants with severe periodontal disease at baseline. Here, we extend the study with an additional 8 years of follow-up, and conduct analyses with updated periodontal disease status and NHL subtypes. The HPFS is an ongoing prospective cohort study of 51,529 men in the U.S. Between baseline in 1986 and 2012, 875 cases of NHL were diagnosed, including 290 chronic lymphocytic leukemia/small lymphocytic lymphomas (CLL/SLL), 85 diffuse large B-cell lymphomas, and 91 follicular lymphomas. We performed multivariable Cox proportional hazards regression to evaluate associations of interest. History of periodontal disease at baseline was positively associated with risk of NHL overall (hazard ratio $(\mathrm{HR})=1.26,95 \%$ confidence interval (CI): 1.06-1.49) and CLL/SLL (HR $=1.41,95 \%$ CI: 1.04-1.90). With updated periodontal status, HRs were 1.30, (95\% CI: 1.11-1.51) for NHL overall and 1.41 (95\% CI: 1.08-1.84) for CLL/SLL. In contrast, after adjusting for periodontal disease, tooth loss was inversely associated with NHL, suggesting that other causes or consequences of tooth loss may have different implications for NHL etiology. Our findings suggest that periodontal disease is a risk factor for NHL. Whether

Author Contributions

All authors were involved with acquisition, analysis, or interpretation of data. D.S.M. conceived and designed the study, with input from K.A.B., B.M.B. and E.G. K.A.B. and D.S.M. performed statistical analyses. K.A.B., J.S., A.E., B.M.B., E.G., and D.S.M. interpreted the results. K.A.B. wrote the first draft of the manuscript, which was critically revised and approved by all authors.

Conflicts of Interest

The authors declare no conflicts of interest. 
periodontal disease is a direct or indirect cause of NHL, or is a marker of underlying systemic inflammation and/or immune dysregulation, warrants further investigation.

\section{Keywords}

periodontal disease; periodontitis; non-Hodgkin lymphoma; epidemiology; risk

\section{Introduction}

Periodontal disease manifests as chronic inflammation of the gum and can lead to loss of bone and connective tissue supporting the tooth, resulting in tooth loss. Tooth loss can be a consequence of other factors such as dental caries, injury, or orthodontic treatment. However, periodontal disease is the leading cause for most cases of tooth loss in older populations [1-5]. Advanced periodontal disease also has well-established systemic inflammatory effects, extending beyond the oral cavity [6]. Further, there is increasing evidence that periodontal disease is linked to chronic diseases, including cardiovascular disease [7, 8], stroke [9], diabetes [10], and cancer [11-14].

Periodontal disease may impact cancer risk through systemic immune dysregulation, which is a hallmark feature of non-Hodgkin lymphoma (NHL). Severe immunosuppression, including inherited and acquired conditions, is the most well-established risk factor for NHL. Immune-modulating stimuli and exposures are also associated with NHL risk [15, 16]; however, whether subclinical immunosuppression plays an important role in lymphomagenesis has not been determined. As the pathoetiology of NHL involves lymphocyte proliferation and hyperactivation [17], a role for chronic inflammation is also strongly suspected as a contributing factor. Indeed, autoimmune diseases resulting in inflammation and chronic antigenic stimulation, such as Sjögren syndrome and systemic lupus erythematosus, have been consistently linked to increased NHL risk [18-21]. In addition, recent studies, including our own preliminary analyses in the Health Professionals Follow-up Study, have shown that elevated levels of specific cytokines and other inflammatory markers measured in pre-diagnostic serum predict future risk of NHL $[16,17$, 22-25].

In an earlier prospective cohort analysis within the Health Professionals Follow-Up Study (HPFS), we observed a $31 \%$ higher risk of non-Hodgkin lymphoma (NHL) among participants who reported having periodontal disease with bone loss at baseline [26]. Here, we extend the analysis with an additional 8 years of follow-up, and, for the first time, conduct analyses by major histological subtypes of NHL. NHL is a heterogeneous group of diseases, with over 50 recognized histologic subtypes [27] and, in the past decade, convincing evidence has emerged to support both commonality and heterogeneity in risk factor associations across subtypes [20, 28]. For example, some risk factors, such as inherited or acquired immunosuppression, are thought to be shared across all NHL, whereas others, such as certain viral or bacterial infections, are specific to certain subtypes. This new knowledge has led to the expectation, as recommended by the International Lymphoma Epidemiology Consortium (InterLymph), that all new epidemiologic studies of NHL include 
consideration of possible etiologic heterogeneity across common histologic subtypes [29]. Given that the pathogenesis of NHL remains largely unknown and well-established risk factors are few, it is difficult to hypothesize a priori which subtypes might be associated with periodontal disease. However, immune dysregulation and inflammation (e.g., uncontrolled B cell proliferation) are hallmark features of all NHL subtypes; therefore, it is plausible that risk factors associated with immunomodulation and/or inflammation (such as periodontal disease) could be associated with several or possibly all NHL subtypes. Identifying risk factors that are either common or specific to NHL subtypes in agnostic analyses has great potential to contribute insights to mechanisms of lymphomagenesis and etiology.

\section{Methods}

\section{Study participants}

The prospective HPFS was established among 51,529 men between ages 40 to 75 years who completed a self-administered baseline questionnaire in 1986. Participants are followed via biennial mailed questionnaire which queries demographic factors, lifestyle habits such as smoking and physical activity, diet, medication use, and medical history. From the baseline population, we excluded men who had a history of cancer (except for non-melanoma skin cancer) ( $\mathrm{n}=1989)$, had an unknown date of NHL diagnosis $(\mathrm{n}=14)$, were missing data on periodontal disease or tooth loss $(n=1433)$, were missing data on smoking history $(n=1894)$, or were ineligible or requested to be withdrawn from the study $(n=64)$, which left a total of 46,147 men in the analytic cohort. Vital status was identified from the National Death Index, report from next-of-kin or the post office (i.e., when a questionnaire mailed to a deceased participant was returned). The follow-up rate for the HPFS cohort is greater than $96 \%$.

This study was approved by the Human Subjects Committee of the Harvard T.H. Chan School of Public Health. Informed consent was implied by return of the baseline questionnaire.

\section{Case ascertainment}

Incident NHL diagnoses were self-reported on biennial follow-up questionnaires and confirmed by review of medical records and pathology reports (98\%), death certificates, or self-confirmed by the participant. Cases were defined according to the International Classification of Diseases, Eighth Revision (ICD-8) codes, 200, 202, and 204.1. Major histologic subtypes of NHL were determined according to the World Health Organization (WHO) classification of lymphomas [27] based on morphology and immunophenotype information available in medical records and the pathology report and consistent with recent International Lymphoma Epidemiology (InterLymph) Consortium guidelines [30, 31]. For diagnoses of chronic lymphocytic leukemia / small lymphocytic lymphoma (CLL/SLL) and follicular lymphoma (FL), immunophenotype information was not required for tissue diagnoses as it was considered that morphology alone can reliably diagnose these histology subtypes [27]. We confirmed 875 incident NHL diagnoses between 1986 and 2012, including 290 cases of CLL/SLL, 85 cases of diffuse large B-cell lymphoma (DLBCL), and 91 cases of FL. Other B cell and T cell subtypes were reported, but these were too few for meaningful analysis. 


\section{Exposure assessment}

At baseline, participants of the HPFS were asked whether they had a history of periodontal disease with bone loss. Self-reported periodontal disease was validated among 140 dentists [32] and 212 non-dentists [33] in the HPFS through a review of dental radiographs from individuals with and without a self-reported history of periodontal disease, with high positive and negative predictive values ( $\searrow_{0} .76$ and $\searrow_{0} .69$, respectively). In addition, participants updated their periodontal disease status on each biennial questionnaire during follow-up. Participants also reported number of natural teeth at baseline. Self-reported number of teeth was highly correlated with the actual number of teeth on clinical assessment in a general population $(\mathrm{r}=0.97)$ [34].

\section{Assessment of covariates}

Geographic region at cohort entry is known based on mailing addresses. Participants reported their age, race, weight, height, smoking history, alcohol consumption, diabetes history, and whether they regularly used non-steroidal anti-inflammatory drugs (NSAIDs) (e.g., acetaminophen, aspirin, or ibuprofen) on baseline questionnaires. We calculated body mass index (BMI) from weight and height (i.e., $\mathrm{kg} / \mathrm{m}^{2}$ ) as a measure of adiposity. Subsequent questionnaires also queried smoking and diabetes diagnoses; these variables were treated as time-varying in analyses.

\section{Statistical analysis}

Person-time accrued for each participant from January 1986 (i.e., the mailing date of the 1986 questionnaire) to the earliest among dates of NHL diagnosis, death, or January 2012 (end of follow-up). The total accrued person-time was 1,013,168 person-years (mean followup per person $=22$ years). We calculated hazard ratios and $95 \%$ confidence intervals using multivariable Cox proportional hazards regression models, stratifying jointly by calendar year of the current questionnaire cycle and age in years (i.e., the time scale), for risk of NHL associated with periodontal disease status at baseline and updated throughout follow-up, to represent chronic and more recent periodontal disease development, respectively. Once a participant reported having periodontal disease, follow-up status was always periodontal disease (given it is a chronic condition that does not resolve). All multivariable models were adjusted for potential confounders and putative risk factors for NHL including race (White, non-White), BMI $\left(<23,23-<25,25-<27,27-<30\right.$, and $\left.30+\mathrm{kg} / \mathrm{m}^{2}\right)$ at baseline, current smoking status (never, past, current), geographic region (West, Midwest, South, Northeast, and Pacific/unknown), current history of diabetes (yes, no), NSAID use at baseline, and tooth loss at baseline (25-32, 17-24, and 0-16 natural teeth remaining). Tooth loss at baseline was included in multivariable models as a proxy for unmeasured potential confounders such as socioeconomic status and access to dental care. To account for missing values for BMI, we included a missing indicator category. Alcohol consumption was not found to be an important confounder in these analyses and therefore was not retained in final models. Separate models were fit for all NHL and its most common histologic subtypes: CLL/SLL, DLBCL, and FL. We used a contrast test, which followed an approximate $\chi^{2}$ distribution, to test whether associations of periodontal disease with major NHL histologic 
subtypes (i.e., CLL/SLL, DLBCL, and FL) differed significantly [35] [36]. For NHL overall, we also conducted an analysis with follow-up starting in 2004 [as a direct comparison with our earlier report [26]] and evaluated potential effect modification in analyses stratified by smoking history, BMI, race, and age. Cross-classifications of periodontal disease status with different baseline teeth number were also examined in relation to risk. Finally, we conducted a sensitivity analysis excluding men who reported a history of rheumatoid arthritis at baseline ( $\mathrm{n}=1269$ ). All analyses were conducted using SAS version 9.3 for UNIX (SAS Institute, Cary, NC).

\section{Results}

At baseline in 1986, men with a history of periodontal disease were older than men with no history of periodontal disease (mean ages 58.3 and 53.7 years, respectively) and men with a history of periodontal disease were more likely to have fewer than 25 natural teeth remaining (29\%) compared to those with no history of periodontal disease (14\%). Men with a history of periodontal disease were also much more likely to be current or past smokers $(80 \%)$ than those with no periodontal disease (50\%). Alcohol intake was slightly higher among men with a history of periodontal disease compared to those with no history of periodontal disease. A slightly higher percent of men with periodontal disease lived in the Northeast compared to those without periodontal disease. Diabetes was relatively rare in both groups $(\mathbf{5} \%$ ) while characteristics such as race and BMI did not differ by periodontal disease status (Table 1).

In multivariable analyses adjusting for age, tooth loss, and other potential confounders, men with a history of periodontal disease with bone loss at baseline had a $26 \%$ higher risk of being diagnosed with NHL compared with those with no reported history of periodontal disease (HR: 1.26; 95\% CI: 1.06, 1.49). Positive associations were noted for both CLL/SLL (HR: $1.41 ; 95 \%$ CI: 1.04, 1.90) and DLBCL (HR: 1.35; 95\% CI: 0.77, 2.37), while there was no apparent association with FL. Similar trends were observed in analyses incorporating updated periodontal disease status (Table 2). There was no evidence of heterogeneity in associations by histologic subtype of NHL (p-heterogeneity: 0.19 for baseline periodontal disease status and 0.44 for updated periodontal disease status).

In analyses of the cross-classified exposure variables, the increase in risk of NHL associated with periodontal disease was observed only among those with fewer missing teeth (at least 25 remaining teeth, HR: 1.25; 95\% CI: 1.02, 1.52); those with periodontal disease and more missing teeth (24 or fewer remaining teeth) did not have a higher risk of NHL (HR: 0.98; 95\% CI: 0.74, 1.30). Results were somewhat stronger when we considered follow-up beginning in 2004: for history of periodontal disease at baseline, the multivariable-adjusted HR was 1.42 (95\% CI: 1.04, 1.94) and for updated periodontal disease status, the multivariable-adjusted HR was 1.57 (95\% CI: 1.20, 2.04); the corresponding HRs for men with fewer missing teeth (at least 25 remaining teeth were 1.51 (95\% CI: 1.07, 2.13) and 1.77 (95\% CI: 1.33, 2.34).

In contrast to positive associations observed for periodontal disease, tooth loss was inversely associated with NHL after adjusting for periodontal disease status: compared to the 
reference group of men with 25-32 teeth remaining, the HRs were 0.75 for 17-24 teeth ( $95 \%$ CI: $0.60,0.94)$ and 0.80 for $0-16$ teeth $(95 \%$ CI: $0.59,1.09)$. Inverse associations of tooth loss with CLL/SLL were also noted, while no clear patterns were observed for either DLBLC or FL; however, the subtype analyses may have been limited by small case counts (Table 2).

It should be highlighted that estimates were essentially unchanged in models that adjusted for age and tooth loss only (data not shown), suggesting little evidence of confounding by other covariates. In addition, results were very similar in sensitivity analyses excluding men with a history of rheumatoid arthritis (HR: $1.23 ; 95 \%$ CI: $1.03,1.47$ ) and in multivariable models that did not adjust for baseline tooth loss (HR: 1.20; 95\% CI: 1.01, 1.42). However, in stratified analyses, associations of periodontal disease with NHL were stronger among past (HR: 1.31; 95\% CI: 1.05, 1.63) and current smokers (HR: 2.59; 95\% CI: 1.05, 6.35) than among never smokers (HR: 1.16 ; $95 \%$ CI: $0.83,1.61$ ). The association was also stronger for older men age $>65$ years and Whites, but statistical power was limited for both younger men and non-Whites. Finally, there was no evidence of effect modification by BMI (Table 3).

\section{Discussion}

In this large, prospective study of male health professionals, we observed positive associations between periodontal disease and future development of NHL, with hazard ratios ranging from 1.26 to 1.30 for NHL overall. We also noted a stronger positive association for CLL/SLL, a weaker positive association with DLBCL, and no association for FL. While we found no evidence of statistically significant heterogeneity in effects across the three subtypes we evaluated separately, these results should be interpreted with caution due to limited statistical power in subtype analyses. In contrast, tooth loss was inversely associated with NHL among those who did not have a history of periodontal disease.

In a recent prospective study of 1,337 postmenopausal women, compared with those without periodontal disease, severe periodontal disease - assessed objectively by measuring oral alveolar crestal height on oral radiographs - was associated with a two-fold higher risk of hematological cancers, including leukemia, Hodgkin lymphoma, NHL, and multiple myeloma (HR: 2.09; 95\% CI: 0.68, 6.47). However, analyses of specific hematological cancers, including distinct NHL subtypes, were not possible given that only 24 cases were identified (including 11 exposed cases) [37]. No association between periodontitis and hematological cancers was observed in a nationwide study in Taiwan [38]. In a Swedish registry-based case-control study, gingivitis and periodontitis was found to be associated with increased risk of lymphoplasmacytic lymphoma/Waldenström macroglobulinemia (odds ratio: 1.9; 95\% CI: 1.3, 2.7) [39], a rarer subtype of NHL [40]. With the exception of our earlier report in the HPFS [26], to date, no other epidemiologic studies have published associations of periodontal disease and NHL overall or by histologic subtypes.

While these associations need to be confirmed in other prospective studies, there is strong biological plausibility for our findings of positive associations between periodontal disease and NHL risk. Severe immune deficiency is well established to increase the risk of NHL 
[27]. Accumulating evidence shows that not only severe immune deficiency but also conditions that trigger chronic immune stimulation, such as autoimmune diseases and certain infections have etiologic roles in NHL [15, 18, 41, 42]. Therefore, periodontal disease could influence future NHL risk through pathways involving immune system dysregulation [43] or chronic systemic inflammation [44]. Oral pathogens, such as $P$. gingivalis, could also have direct or indirect roles in lymphomagenesis [44, 45].

Alternatively, periodontal disease could be a marker of host factors associated with poor control of the immune response to infections (e.g., subclinical immunosuppression) [6], increasing susceptibility to both periodontal disease and NHL.

In contrast to our findings of a positive association between periodontal disease and NHL, we found that tooth loss was inversely associated with NHL among those without periodontal disease. One possible explanation for this finding is that loss of teeth could lead to resolution of local oral inflammation, which could impact both the oral microbiome and the immune response. For example, individuals who have lost teeth earlier in life may not have been exposed to periodontal infection later in life [9]. However, among 243 diseasefree HPFS participants, we noted that those with more missing teeth had higher levels of Creactive protein (CRP), a biomarker of systemic inflammation, than those without tooth loss ( $\mathrm{p}=0.04$; unpublished data), suggesting that factors besides CRP may be important in associations of tooth loss with NHL risk. Another explanation is that causes of tooth loss other than periodontal disease may lead to a decreased risk of NHL. Alternatively, this could be a chance finding. The inverse association we observed for tooth loss likely explains the lack of a positive association of periodontal disease with NHL among those with tooth loss, as the associations for periodontal disease history and tooth loss are in opposite directions. Further research is warranted to reconcile these findings.

Several limitations of our analysis should be noted. First, periodontal disease was selfreported and while we have demonstrated the validity of our exposure assessment in prior studies [32, 33], exposure misclassification is possible. Given the prospective study design, any misclassification of exposure would be expected to be non-differential with respect to NHL diagnosis; therefore, observed associations may be attenuated. Second, we lacked data on causes of tooth loss, timing of tooth loss (e.g., childhood or adulthood), and treatment received for periodontal disease and were unable to evaluate possible effects of these factors. Third, while we were able to evaluate the most common NHL subtypes in our cohort, due to small numbers, we had limited ability to examine less common subtypes. Also, information on organ site of NHL is not routinely collected in the HPFS; therefore, we could not evaluate whether the association with periodontal disease is stronger for oral lymphomas. However, lymphomas of the oral cavity are very rare, representing <1\% of NHLs [46]. Finally, no exclusions were made for HIV status, other viral or bacterial infections, or organ transplantation, endpoints that have not been formally assessed in follow-up. These factors could be related to both periodontal disease and NHL risk; however, the prevalence of these conditions is expected to be rare and therefore any bias due to confounding by these factors is likely to be minimal.

Our study also has a number of important strengths, including its prospective design and long-term follow-up. The long lag (up to 26 years) between reported periodontal disease and 
most diagnoses of NHL suggests that periodontal disease is not likely a consequence of the cancer. With comprehensive individual-level information on demographics, lifestyle factors, and medical history throughout follow-up, we were also able to finely control for possible confounders, such as smoking and diabetes. Finally, our case population of $875 \mathrm{NHL}$ diagnoses allowed us to evaluate, for the first time, associations with common NHL subtypes.

In conclusion, our findings suggest that periodontal disease may represent a novel risk factor for NHL. Further research is needed to determine whether periodontal disease is a direct or indirect cause of NHL, or is a marker of underlying systemic inflammation or immune dysregulation, and also to identify mechanisms for the apparent reduced risk after tooth loss.

\section{Acknowledgments}

We would like to thank the participants and staff of the Health Professionals Follow-up Study for their valuable contributions as well as the following state cancer registries for their help: AL, AZ, AR, CA, CO, CT, DE, FL, GA, ID, IL, IN, IA, KY, LA, ME, MD, MA, MI, NE, NH, NJ, NY, NC, ND, OH, OK, OR, PA, RI, SC, TN, TX, VA, WA, WY. The authors assume full responsibility for analyses and interpretation of these data.

Funding

This work was supported by the National Cancer Institute at the National Institutes of Health (UM1 CA167552, R01 CA166150, R01 CA149445).

\section{References}

1. Ravald N, Johansson CS. Tooth loss in periodontally treated patients: a long-term study of periodontal disease and root caries. J Clin Periodontol. 2012; 39(1):73-79.

2. Chambrone LA, Chambrone L. Tooth loss in well-maintained patients with chronic periodontitis during long-term supportive therapy in Brazil. J Clin Periodontol. 2006; 33(10):759-764. [PubMed: 16899027]

3. Matthews DC, Smith CG, Hanscom SL. Tooth loss in periodontal patients. J Can Dent Assoc. 2001; 67(4):207-210. [PubMed: 11370278]

4. Costa FO, Lages EJ, Cota LO, Lorentz TC, Soares RV, Cortelli JR. Tooth loss in individuals under periodontal maintenance therapy: 5-year prospective study. J Periodontal Res. 2014; 49(1):121-128. [PubMed: 23647520]

5. Chambrone L, Chambrone D, Lima LA, Chambrone LA. Predictors of tooth loss during long-term periodontal maintenance: a systematic review of observational studies. J Clin Periodontol. 2010; 37(7):675-684. [PubMed: 20528960]

6. Hajishengallis G. Periodontitis: from microbial immune subversion to systemic inflammation. Nat Rev Immunol. 2015; 15(1):30-44. [PubMed: 25534621]

7. Humphrey LL, Fu R, Buckley DI, Freeman M, Helfand M. Periodontal disease and coronary heart disease incidence: a systematic review and meta-analysis. J Gen Intern Med. 2008; 23(12):2079_ 2086. [PubMed: 18807098]

8. Lockhart PB, Bolger AF, Papapanou PN, Osinbowale O, Trevisan M, Levison ME, Taubert KA, Newburger JW, Gornik HL, Gewitz MH, et al. Periodontal disease and atherosclerotic vascular disease: does the evidence support an independent association?: a scientific statement from the American Heart Association. Circulation. 2012; 125(20):2520-2544. [PubMed: 22514251]

9. Lafon A, Pereira B, Dufour T, Rigouby V, Giroud M, Bejot Y, Tubert-Jeannin S. Periodontal disease and stroke: a meta-analysis of cohort studies. Eur J Neurol. 2014; 21(9):1155-1161. e1166-1157. [PubMed: 24712659] 
10. Preshaw PM, Alba AL, Herrera D, Jepsen S, Konstantinidis A, Makrilakis K, Taylor R. Periodontitis and diabetes: a two-way relationship. Diabetologia. 2012; 55(1):21-31. [PubMed: 22057194]

11. Michaud DS, Kelsey KT, Papathanasiou E, Genco CA, Giovannucci E. Periodontal disease and risk of all cancers among male never smokers: an updated analysis of the Health Professionals Followup Study. Ann Oncol. 2016

12. Meyer MS, Joshipura K, Giovannucci E, Michaud DS. A review of the relationship between tooth loss, periodontal disease, and cancer. Cancer Causes Control. 2008; 19(9):895-907. [PubMed: 18478344]

13. Fitzpatrick SG, Katz J. The association between periodontal disease and cancer: a review of the literature. J Dent. 2010; 38(2):83-95. [PubMed: 19895866]

14. Zeng XT, Deng AP, Li C, Xia LY, Niu YM, Leng WD. Periodontal disease and risk of head and neck cancer: a meta-analysis of observational studies. PLoS One. 2013; 8(10):e79017. [PubMed: 24194957]

15. Grulich AE, Vajdic CM, Cozen W. Altered immunity as a risk factor for non-Hodgkin lymphoma. Cancer Epidemiol Biomarkers Prev. 2007; 16(3):405-408. [PubMed: 17337643]

16. Saberi Hosnijeh F, Krop EJ, Scoccianti C, Krogh V, Palli D, Panico S, Tumino R, Sacredote C, Nawroly N, Portengen L, et al. Plasma cytokines and future risk of non-Hodgkin lymphoma (NHL): a case-control study nested in the Italian European Prospective Investigation into Cancer and Nutrition. Cancer Epidemiol Biomarkers Prev. 2010; 19(6):1577-1584. [PubMed: 20501772]

17. Vendrame E, Martinez-Maza O. Assessment of pre-diagnosis biomarkers of immune activation and inflammation: insights on the etiology of lymphoma. Journal of proteome research. 2011; 10(1): 113-119. [PubMed: 20886858]

18. Ekstrom Smedby K, Vajdic CM, Falster M, Engels EA, Martinez-Maza O, Turner J, Hjalgrim H, Vineis P, Seniori Costantini A, Bracci PM, et al. Autoimmune disorders and risk of non-Hodgkin lymphoma subtypes: a pooled analysis within the InterLymph Consortium. Blood. 2008; 111(8): 4029-4038. [PubMed: 18263783]

19. Smedby KE, Hjalgrim H, Askling J, Chang ET, Gregersen H, Porwit-MacDonald A, Sundstrom C, Akerman M, Melbye M, Glimelius B, et al. Autoimmune and chronic inflammatory disorders and risk of non-Hodgkin lymphoma by subtype. J Natl Cancer Inst. 2006; 98(1):51-60. [PubMed: 16391371]

20. Morton LM, Slager SL, Cerhan JR, Wang SS, Vajdic CM, Skibola CF, Bracci PM, de Sanjose S, Smedby KE, Chiu BC, et al. Etiologic heterogeneity among non-Hodgkin lymphoma subtypes: the InterLymph Non-Hodgkin Lymphoma Subtypes Project. J Natl Cancer Inst Monogr. 2014; 2014(48):130-144. [PubMed: 25174034]

21. Anderson LA, Gadalla S, Morton LM, Landgren O, Pfeiffer R, Warren JL, Berndt SI, Ricker W, Parsons R, Engels EA. Population-based study of autoimmune conditions and the risk of specific lymphoid malignancies. Int J Cancer. 2009

22. Purdue MP, Lan Q, Bagni R, Hocking WG, Baris D, Reding DJ, Rothman N. Prediagnostic serum levels of cytokines and other immune markers and risk of non-hodgkin lymphoma. Cancer Res. 2011; 71(14):4898-4907. [PubMed: 21632552]

23. Purdue MP, Hofmann JN, Kemp TJ, Chaturvedi AK, Lan Q, Park JH, Pfeiffer RM, Hildesheim A, Pinto LA, Rothman N. A prospective study of 67 serum immune and inflammation markers and risk of non-Hodgkin lymphoma. Blood. 2013; 122(6):951-957. [PubMed: 23814017]

24. Edlefsen KL, Martinez-Maza O, Madeleine MM, Magpantay L, Mirick DK, Kopecky KJ, LaCroix AZ, De Roos AJ. Cytokines in serum in relation to future non-Hodgkin lymphoma risk: evidence for associations by histologic subtype. Int J Cancer. 2014; 135(4):913-922. [PubMed: 24488825]

25. Conroy SM, Maskarinec G, Morimoto Y, Franke AA, Cooney RV, Wilkens LR, Goodman MT, Hernadez BY, Le Marchand L, Henderson BE, et al. Non-hodgkin lymphoma and circulating markers of inflammation and adiposity in a nested case-control study: the multiethnic cohort. Cancer Epidemiol Biomarkers Prev. 2013; 22(3):337-347. [PubMed: 23300021]

26. Michaud DS, Liu Y, Meyer M, Giovannucci E, Joshipura K. Periodontal disease, tooth loss, and cancer risk in male health professionals: a prospective cohort study. Lancet Oncol. 2008; 9(6):550558. [PubMed: 18462995] 
27. Swerdlow, SH., Campo, E., Harris, NL., Jaffe, ES., Pileri, SA., Stein, H., Thiele, J., Vardiman, JW. WHO Classification of Tumours of Haematopoietic and Lymphoid Tissues. Lyon, France: International Agency for Research on Cancer (IARC) Press; 2008.

28. Morton LM, Wang SS, Cozen W, Linet MS, Chatterjee N, Davis S, Severson RK, Colt JS, Vasef MA, Rothman N, et al. Etiologic heterogeneity among non-Hodgkin lymphoma subtypes. Blood. 2008; 112(13):5150-5160. [PubMed: 18796628]

29. Morton LM, Sampson JN, Cerhan JR, Turner JJ, Vajdic CM, Wang SS, Smedby KE, de Sanjose S, Monnereau A, Benavente Y, et al. Rationale and Design of the International Lymphoma Epidemiology Consortium (InterLymph) Non-Hodgkin Lymphoma Subtypes Project. J Natl Cancer Inst Monogr. 2014; 2014(48):1-14. [PubMed: 25174022]

30. Morton LM, Turner JJ, Cerhan JR, Linet MS, Treseler PA, Clarke CA, Jack A, Cozen W, Maynadie M, Spinelli JJ, et al. Proposed classification of lymphoid neoplasms for epidemiologic research from the Pathology Working Group of the International Lymphoma Epidemiology Consortium (InterLymph). Blood. 2007; 110(2):695-708. [PubMed: 17389762]

31. Turner JJ, Morton LM, Linet MS, Clarke CA, Kadin ME, Vajdic CM, Monnereau A, Maynadie M, Chiu BC, Marcos-Gragera R, et al. InterLymph hierarchical classification of lymphoid neoplasms for epidemiologic research based on the WHO classification (2008): update and future directions. Blood. 2010; 116(20):e90-98. [PubMed: 20699439]

32. Joshipura KJ, Douglass CW, Garcia RI, Valachovic R, Willett WC. Validity of a self-reported periodontal disease measure. J Public Health Dent. 1996; 56(4):205-212. [PubMed: 8906704]

33. Joshipura KJ, Pitiphat W, Douglass CW. Validation of self-reported periodontal measures among health professionals. J Public Health Dent. 2002; 62(2):115-121. [PubMed: 11989206]

34. Douglass CW, Berlin J, Tennstedt S. The validity of self-reported oral health status in the elderly. J Public Health Dent. 1991; 51(4):220-222. [PubMed: 1941773]

35. Smith-Warner SA, Spiegelman D, Ritz J, Albanes D, Beeson WL, Bernstein L, Berrino F, van den Brandt PA, Buring JE, Cho E, et al. Methods for pooling results of epidemiologic studies: the Pooling Project of Prospective Studies of Diet and Cancer. Am J Epidemiol. 2006; 163(11):10531064. [PubMed: 16624970]

36. Anderson, TW. Introduction to Multivariate Statistics. 2. New York: John Wiley \& Sons; 1984.

37. Mai X, LaMonte MJ, Hovey KM, Freudenheim JL, Andrews CA, Genco RJ, Wactawski-Wende J. Periodontal disease severity and cancer risk in postmenopausal women: the Buffalo OsteoPerio Study. Cancer Causes Control. 2016; 27(2):217-228. [PubMed: 26661782]

38. Wen BW, Tsai CS, Lin CL, Chang YJ, Lee CF, Hsu CH, Kao CH. Cancer risk among gingivitis and periodontitis patients: a nationwide cohort study. QJM. 2014; 107(4):283-290. [PubMed: 24336850]

39. Kristinsson SY, Koshiol J, Bjorkholm M, Goldin LR, McMaster ML, Turesson I, Landgren O. Immune-related and inflammatory conditions and risk of lymphoplasmacytic lymphoma or Waldenstrom macroglobulinemia. J Natl Cancer Inst. 2010; 102(8):557-567. [PubMed: 20181958]

40. Al-Hamadani M, Habermann TM, Cerhan JR, Macon WR, Maurer MJ, Go RS. Non-Hodgkin lymphoma subtype distribution, geodemographic patterns, and survival in the US: A longitudinal analysis of the National Cancer Data Base from 1998 to 2011. Am J Hematol. 2015; 90(9):790795. [PubMed: 26096944]

41. Edlefsen, KL., Martinez-Maza, O., Madeleine, MM., Magpantay, L., Mirick, DK., Kopecky, KJ., Lacroix, AZ., De Roos, AJ. International journal of cancer Journal international du cancer. 2014. Cytokines in serum in relation to future non-Hodgkin lymphoma risk: Evidence for associations by histologic subtype.

42. Vendrame E, Hussain SK, Breen EC, Magpantay LI, Widney DP, Jacobson LP, Variakojis D, Knowlton ER, Bream JH, Ambinder RF, et al. Serum levels of cytokines and biomarkers for inflammation and immune activation, and HIV-associated non-Hodgkin B-cell lymphoma risk. Cancer epidemiology, biomarkers \& prevention : a publication of the American Association for Cancer Research, cosponsored by the American Society of Preventive Oncology. 2014; 23(2):343349. 
43. Schmidt J, Jentsch H, Stingu CS, Sack U. General immune status and oral microbiology in patients with different forms of periodontitis and healthy control subjects. PLoS One. 2014; 9(10):e109187. [PubMed: 25299619]

44. Hayashi C, Gudino CV, Gibson FC 3rd, Genco CA. Review: Pathogen-induced inflammation at sites distant from oral infection: bacterial persistence and induction of cell-specific innate immune inflammatory pathways. Mol Oral Microbiol. 2010; 25(5):305-316. [PubMed: 20883220]

45. Garrett WS. Cancer and the microbiota. Science. 2015; 348(6230):80-86. [PubMed: 25838377]

46. Ferry, JA., Harris, NL. Lymphomas and lymphoid hyperplasia in head and neck sites. In: Pilch, BZ., editor. Head and neck surgical pathology. Lippincott Williams and Wilkins; 2001. p. 476-533. 


\section{Novelty and Impact}

In this prospective cohort analysis, history of periodontal disease was associated with a 26-30\% increased risk of non-Hodgkin lymphoma. Periodontal disease may be a novel risk factor for non-Hodgkin lymphoma. 


\section{Table 1}

Age-standardized baseline (1986) characteristics of participants in the Health Professionals Follow-up Study, by periodontal disease $(n=46,147)$.

\begin{tabular}{|c|c|c|}
\hline & No periodontal disease $(n=38,651)$ & History of periodontal disease $(n=7,496)$ \\
\hline Age, years & $53.7(9.7)$ & $58.3(9.2)$ \\
\hline BMI, $\mathrm{kg} / \mathrm{m}^{2}$ & $24.9(5.0)$ & $25.0(5.4)$ \\
\hline Height, $\mathrm{cm}$ & $70.1(3.4)$ & $69.9(3.8)$ \\
\hline \multicolumn{3}{|l|}{ Tooth loss } \\
\hline $25-32$ teeth remaining & $86 \%$ & $71 \%$ \\
\hline 17-24 teeth remaining & $10 \%$ & $18 \%$ \\
\hline $0-16$ teeth remaining & $4 \%$ & $11 \%$ \\
\hline \multicolumn{3}{|l|}{ Race } \\
\hline White & $94 \%$ & $91 \%$ \\
\hline Non-white & $6 \%$ & $9 \%$ \\
\hline \multicolumn{3}{|l|}{ Smoking } \\
\hline Never & $50 \%$ & $30 \%$ \\
\hline Past & $42 \%$ & $53 \%$ \\
\hline Current & $9 \%$ & $17 \%$ \\
\hline Alcohol intake, g/day & $11.1(15.2)$ & $12.8(16.8)$ \\
\hline Diabetes & $3 \%$ & $5 \%$ \\
\hline Physical activity, METS & $19.5(24.9)$ & $18.3(23.0)$ \\
\hline Regular NSAID use & $37 \%$ & $37 \%$ \\
\hline \multicolumn{3}{|l|}{ Geographic region } \\
\hline Northeast & $22 \%$ & $30 \%$ \\
\hline Midwest & $28 \%$ & $21 \%$ \\
\hline South & $27 \%$ & $28 \%$ \\
\hline West & $22 \%$ & $19 \%$ \\
\hline
\end{tabular}

Means (standard deviation) or percentages are shown. NSAID: non-steroidal anti-inflammatory drugs; METS: metabolic equivalents. 


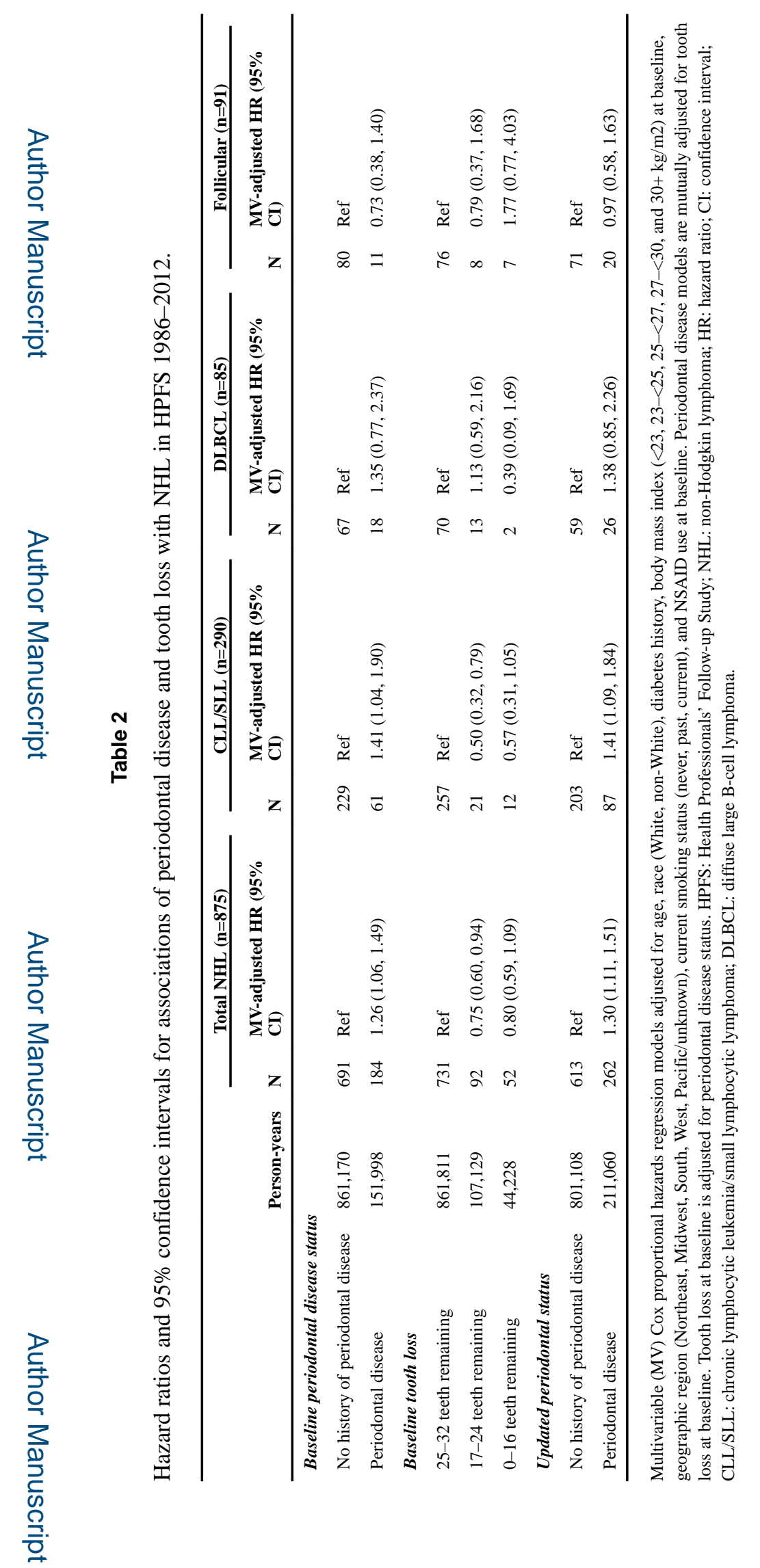

Int J Cancer. Author manuscript; available in PMC 2018 March 01. 
Table 3

Hazard ratios and 95\% confidence intervals for associations of periodontal disease with NHL in HPFS 19862012, stratified by smoking, BMI, race, and age. *

\begin{tabular}{llll}
\hline Periodontal disease status: & Yes/No & MV-adjusted HR $(\mathbf{9 5 \%}$ CI) & P-value interaction \\
\hline Never smokers & $47 / 298$ & $1.16(0.83,1.61)$ & \\
Past smokers & $123 / 363$ & $1.31(1.05,1.63)$ & \\
Current smokers & $14 / 30$ & $2.59(1.05,6.35)$ & 0.74 \\
BMI $<25 \mathrm{~kg} / \mathrm{m}^{2}$ & $85 / 324$ & $1.32(1.02,1.70)$ & \\
BMI $25 \mathrm{~kg} / \mathrm{m}^{2}$ & $99 / 367$ & $1.28(1.01,1.61)$ & 0.94 \\
White & $174 / 660$ & $1.29(1.08,1.54)$ & \\
Non-White & $10 / 31$ & $0.81(0.31,2.15)$ & 0.84 \\
Age 55 & $33 / 219$ & $1.10(0.75,1.61)$ & \\
Age $>65$ & $151 / 472$ & $1.33(1.09,1.62)$ & 0.47 \\
\hline
\end{tabular}

* Based on baseline periodontal disease status in 1986. Multivariable (MV) Cox proportional hazards regression models adjusted for missing teeth, race, diabetes, smoking history, body mass index (BMI).NHL: non-Hodgkin lymphoma; HR: hazard ratio; CI: confidence interval. 